\title{
A GÊNESE E O DESENVOLVIMENTO HISTÓRICO DO ENSINO DE ENFERMAGEM NO BRASIL
}

\section{THE BEGINNINGS AND THE DEVELOPMENT OF NURSING EDUCATION IN BRAZIL}

Tatiana Gabriela Brassea Galleguillos* Maria Amélia de Campos Oliveira**

GALlEGUillos, TGB.; OLIVEIRA, MAC. A gênese e o desenvolvimento histórico do ensino de enfermagem no Brasil. Rev Esc Enf USP, v.35, n. 1,p. 80-7, mar. 2001.

\section{RESUMO}

Buscou-se reconstruir a história do ensino de enfermagem no Brasil desde a criação da Escola de Enfermagem Anna Nery, em 1922, através de seus programas de ensino, de 1923, 1926 e 1949, e dos currículos mínimos para o ensino de enfermagem no país, de 1962, 1972 e 1994. Apesar da enfermagem moderna no Brasil ter sido instituída para formar enfermeiras para atuar em saúde pública, desde o início a formação foi centrada no espaço hospitalar e voltada para o estudo sistemático das doenças, sem priorizar as questões vinculadas à saúde pública. Mesmo o currículo mínimo de 1994, construído coletivamente a partir de uma proposta contra-hegemônica, preservou a subdivisão em especialidades médicas, própria do modelo flexneriano. Verifica-se que continua presente o modelo biomédico, individualizado e hospitalocêntrico que marcou o ensino de enfermagem desde as suas origens no Brasil, e que a formação não está voltada para as necessidades de saúde da população, sendo portanto antagônica aos pressupostos da Saúde Coletiva.

PALAVRAS-CHAVE: Enfermagem. Educação em enfermagem. Enfermagem (Brasil).

\begin{abstract}
Nursing education history in Brazil was re-visited, beginning with the foundation of the Anna Nery School of Nursing in 1922, followed by the analysis of the teaching programs of 1923, 1926 and 1949, and of the national curriculum for Nursing education of 1962, 1972 and 1994. In spite of the fact that modern Nursing in Brazil was established to qualify nurses to work in public health, since the beginning they were trained in hospitals, with the systematic study of diseases, without giving priority to subjects linked to public health. Although the reformulation that resulted in the 1994 curriculum was committed to the construction of an education proposal that was non-hegemonic in Nursing, the subdivision in medical specialties was preserved, as a result of the adoption of the flexnerian model. The biomedical, individualized and hospitalbased model that influenced Nursing education from it origins in Brazil is still present and Nursing education is not focused on the population needs, being therefore antagonistic to the presuppositions of Collective Health.
\end{abstract}

KEYWORDS: Nursing. Nursing education. Nursing (Brazil)

\section{A INSTITUCIONALIZAÇÃO DO ENSINO DE ENFERMAGEM NO BRASIL}

No Brasil, o ensino de Enfermagem iniciou-se oficialmente em 1890, com a promulgação do Decreto n.791, tendo como objetivo preparar enfermeiros e enfermeiras para trabalhar nos hospícios e hospitais civis e militares, nos moldes da escola existente em Salpetrière, na França. O Hospital Nacional dos Alienados havia passado para controle direto do novo Governo Republicano e diante da necessidade da capacitação de pessoal para realizar os cuidados de enfermagem, foi criada a Escola Alfredo

\footnotetext{
* $\quad$ Enfermeira. Mestre em Enfermagem em Saúde Coletiva pela Escola de Enfermagem da Universidade de São Paulo. Email:tatygalleguillos@uol.com.br

** Enfermeira. Professora Doutora do Departamento de Enfermagem em Saúde Coletiva da Escola de Enfermagem da Universidade de São Paulo. E-mail: macampos@usp.br
} 
Pinto, no mesmo ano, dirigida por médicos, que também supervisionavam o ensino. Sua existência, porém, foi ignorada por Jane A. Jackson que, representando o Brasil na reunião do Conselho Internacional de Enfermeiras (ICN) realizada em 1901, não mencionou a existência dessa escola. Isso talvez explique o fato da Escola de Enfermagem Anna Nery ser considerada a primeira escola de enfermagem no Brasil (PAIVA et al, 1999; PAIXÃO,1951; ALCÂNTARA, 1963; CARVALHO, 1972).

Em 1916, foi criada a Escola Prática de Enfermeiras da Cruz Vermelha Brasileira para treinar socorristas voluntários e, em 1920, na mesma escola, foi criado o curso de visitadoras sanitárias (PAIVA et al, 1999). De fato, "a formação de visitadoras sanitárias precede a institucionalização da enfermagem, tanto na Europa, quanto nos Estados Unidos e no Brasil. Nas atividades destas visitadoras repousam as raizes da Enfermagem em Saúde Coletiva..." (SALUM; BERTOLOZZI; OLIVEIRA, 1999). No entanto, no Brasil, as ações das visitadoras foram de caráter emergencial, principalmente devido a falta de conhecimentos básicos das mesmas (FRAENKEL, 1997).

Considera-se, entretanto, que a Enfermagem Moderna foi introduzida no Brasil em 1923, mediante a organização do serviço de enfermeiras do Departamento Nacional de Saúde Pública (DNSP), então dirigido por Carlos Chagas. O ensino sistematizado tinha como propósito formar profissionais que garantissem o saneamento urbano, condição necessária à continuidade do comércio internacional, que se encontrava ameaçado pelas epidemias. Essa capacitação estava a cargo de enfermeiras da Fundação Rockfeller, enviadas ao Brasil com o intuito de organizar o serviço de enfermagem de saúde pública e dirigir uma escola de enfermagem. Esta foi criada em 1922, mas iniciou seu funcionamento em 1923, com o nome de Escola de Enfermagem do DNSP. Em 1926, passou a ser designada Escola de Enfermagem Anna Nery (EEAN) e, em 1931, Escola de Enfermagem da Universidade Federal do Rio de Janeiro.

\section{OS PROGRAMAS E OS CURRÍCULOS MÍNIMOS PARA OS CURSOS DE ENFERMAGEM NO BRASIL}

\subsection{Os programas de ensino de 1923 e 1926}

Como afirmam SALUM; BERTOLOZZI; OLIVEIRA (1999) "a enfermagem profissional no Brasil emergiu na década de 20 sob a influência norte-americana, com a participação das enfermeiras visitadoras ". Assim como a enfermagem inglesa e norte-americana, a enfermagem brasileira institucionalizou-se subordinada à prática médica, ainda que inspirada "por um projeto que se pretendia voltado para o coletivo". Entretanto, segundo RIZZOTTO (1999), os primeiros programas da EEAN confirmam o ensino voltado à assistência hospitalar.

O programa de ensino de 1923 e as exigências feitas para a matrícula das candidatas caracterizaram

o curso, desde o início, como de nível superior, sob total influência das tendências da educação de enfermagem norte-americana. Uma das restrições encontradas para a efetivação do curso como de nível superior foi a precária formação das mulheres brasileiras naquela época, o pouco acesso à educação, realidade distinta daquela encontrada nos Estados Unidos, e portanto, responsável pelo lento desenvolvimento do ensino de enfermagem nesses primeiros anos (ALCANTARA, 1963).

Ao analisar o programa de 1923, RIZZOTTO (1999) observou que este não diferia basicamente do programa instituído nos Estados Unidos em 1917, centrado na formação hospitalar, o que a leva acreditar que houve grande empenho em reproduzir no Brasil o modelo da enfermagem americana, principalmente no que diz respeito à estruturação dos serviços de enfermagem nos hospitais.

A EEAN, também denominada "Escola padrão", teve o seu programa de ensino utilizado como modelo para as escolas criadas posteriormente, reproduzindo de forma hegemônica o currículo norteamericano, direcionado para o trabalho de enfermagem em instituições

hospitalares, atendendo à medicina curativa e hospitalar. Em estudo realizado sobre o rol de disciplinas que compunham o ensino teórico do primeiro programa da Escola Anna Nery, RIZZOTTO (1999) afirma que "somente $11 \%$ das mesmas eram voltadas para a Saúde Pública". A prática nos campos de estágio era quase que toda realizada em instituições hospitalares, à semelhança do que ocorre hoje na maioria das escolas de enfermagem.

As primeiras alterações realizadas compuseram o programa de ensino de 1926 que, no entanto, não apresentou diferenças significativas em relação ao anterior. Ao analisar as cargas horárias de ambos, RIZZOTTO (1999) verificou que houve aumento significativo de disciplinas relacionadas ao atendimento do indivíduo, comprovando novamente a predominância do modelo biomédico e voltado ao

\footnotetext{
10 decreto 20.109/31, regulamentou o exercício da enfermagem no Brasil e instituiu a escola de enfermagem Anna Nery como escola'padrão, para efeito de equiparação de todas as escolas nacionais (CARVALHO, 1976).
} 
corpo individual. A ênfase na formação de base clinica discutir a integração da formação de enfermeiras e evidenciava-se no fato de que mais de $90 \%$ do ensino obstetrizes. A obstetriz integrante da subcomissão não prático era realizado em hospitais. Assim, pode-se concordava com o ensino de obstetrícia nas escolas dizer que na década de 30, o exercício da enfermagem de Enfermagem, constituindo um curso único. no Brasil, que pretendia vinculado à saúde pública, caracterizou-se definitivamente como voltado para o modelo de assistência hospitalar (BARREIRA, 1999).

"Esperava-se, com essas medidas, maior afluxo de candidatos à profissão. Além do mais, os recursos das trinta e cinco escolas de Enfermagem existentes A Associação Brasileira de Enfermagem (ABEn), podiam ser duplamente aproveitados" (CARVALHO, fundada em 12 de agosto de 1926, sob o nome de 1976). O encontro resultou em dois relatórios Associação Nacional de Enfermeiras Diplomadas, distintos, prevalecendo aquele realizado pela ABEn, preocupou-se com a educação desde sua criação e que previa três niveis de formação para a enfermagem: assim permaneceu ao longo de sua existência, o que superior, médio e elementar. O nivel médio formaria o pode ser comprovado nos seus diversos estatutos, técnico de enfermagem em curso de duração de três congressos, documentos das comissões e anos, com acesso ao nível superior. O nível elementar principalmente no seu veículo de maior divulgação, a continuaria formando o auxiliar de enfermagem.

Revista Brasileira de Enfermagem. Em 1945 foi criada a Divisão de Ensino de Enfermagem, posteriormente designada Divisão de Educação, com os objetivos de organizar o ensino quanto ao currículo teórico mínimo e a duração dos estágios para a formação da enfermeira e estabelecer normas para a formação de auxiliares de enfermagem (CARVALHO,1976).

\subsection{0 curriculo de 1949}

A Divisão de Educação da ABEn assumiu a responsabilidade de elaborar o currículo e determinar o regime escolar dos cursos previstos, tarefa desempenhada pela Subcomissão de Currículo que contribuiu para a elaboração e a discussão do projeto que deu origem à Lei n.775/49 que regulamentou o ensino de Enfermagem. A exemplo do currículo norteamericano, o currículo de 1949 continha um grande número de especialidades médicas com conteúdos de enfermagem (GERMANO, 1985; CARVALHO, 1976). Para esta última autora, a enfermagem brasileira adotou o paradigma norte-americano, porém sem dispor dos mesmos avanços tecnológicos e vivenciando outra realidade. O currículo de 1949 era "pouco inovador relacionado ao programa inicial, prevalece a ênfase no fazer, mais do que no pensar, na repetição de técnicas que tolhiam a criatividade das alunas $e$ com a centralização no estado da doença e não do doente" (GARCIA; CHIANCA; MOREIRA, 1995).

Após a publicação da Lei n.775/49, entre 1949 e 1956 as escolas puderam continuar recebendo candidatos apenas com o curso ginasial completo, prazo prorrogado por mais cinco anos pela Lei n.2995/ 56. O baixo nivel de conhecimento das candidatas, entretanto, provocava elevado índice de reprovação devido à dificuldade de acompanhar os estudos. Sendo assim, o VII Congresso Nacional de Enfermagem, em 1954, recomendou a seleção através do vestibular e o uso de testes psicotécnicos para avaliar as condições das ingressantes (CARVALHO, 1976).

Em 1957, reuniu-se uma subcomissão de Diretoras de Escolas de Enfermagem e Obstetrícia para
Em 1960, o projeto de Lei n.2684/60 tentou prorrogar o prazo que as escolas de Enfermagem teriam para aceitar candidatas apenas com o curso ginasial, porém as escolas foram unânimes em votar pela retirada do projeto e pela manutenção do nivel superior para o ensino da enfermagem.

Em dezembro de 1961, foi promulgada a Lei $n$ 4.024/61, de Diretrizes e Bases da Educação Nacional e criado o Conselho Federal de Educação (CFE), que passou a ser o responsável pelo ensino superior. Foi indicada uma comissão de peritos para discutir as diretrizes do ensino de enfermagem, porém a determinação sobre a duração e o currículo dos cursos superiores dependia das novas diretrizes a serem definidas a partir da nova lei. Após inúmeras reuniões, inclusive com o Diretor de Ensino Superior, foi entregue à Diretoria do Ensino Superior o relatório no qual era proposto um curso com duração de quatro anos, distribuído em nove cadeiras de enfermagem e onze disciplinas, com a recomendação que fossem realizados concursos de ingresso e cursos de pósgraduação (CARVALHO, 1976).

\subsection{0 curriculo minimo de 1962}

Em 1962, o Parecer CFE n.271/62 fixou o primeiro currículo mínimo para os cursos de enfermagem, com base em sugestões da Comissão de Peritos de Enfermagem nomeada pelo Ministro da Educação (MEC), da ABEn e das 19 Escolas de Enfermagem do país. Este currículo manteve as disciplinas relacionadas às clínicas especializadas, de caráter curativo. Nele, a disciplina Saúde Pública já não aparecia como obrigatória, mas apenas como conteúdo de especialização (GERMANO, 1985).

Apesar de existir a Comissão de Peritos de Enfermagem, uma comissão do CFE, composta de três médicos, apresentou sugestões que resultaram no Parecer n.271/62 que regulamentou o currículo minimo de enfermagem, reduziu a duração do curso para três anos, introduziu especializações num quarto ano optativo e eliminou a disciplina de Enfermagem 
em Saúde Pública do currículo mínimo, cujo inclusão nos currículos plenos das escolas passou a ser optativa (CARVALHO,1976). A exclusão da disciplina Enfermagem em Saúde Pública restringiu ainda mais a formação da enfermeira, voltada somente ao atendimento individual e curativo, reduzindo a possibilidade das alunas entrarem em contato com esse conteúdo durante a graduação.

A reivindicação para a duração de quatro anos do curso geral de enfermagem permeou todas as discussões posteriores ao Parecer n. 271/62. O período de 1964-1974 caracterizou-se pela consolidação e apogeu do autoritarismo que promoveu reformas institucionais, inclusive na educação. Para GERMANO (1993) a politica educacional desenvolveu-se a partir do controle político e ideológico, com relação direta entre a educação e o modo de produção capitalista, voltado ao acúmulo de capital e descomprometido com o financiamento da educação.

Após a Reforma Universitária de 1968, a Lei n.5.540/68 fixou as normas de organização e funcionamento do ensino superior e sua articulação com o ensino médio. Tal Reforma resultou de um processo iniciado no final da década de $40 \mathrm{com}$ o intuito de modernizar e democratizar o ensino superior do país. Assimilou a experiência do Estado e as demandas estudantis, porém a implantação de um Estado de Segurança Nacional de cunho ditatorial buscou inviabilizar um projeto de universidade crítica e democrática (GERMANO, 1993).

Em 1968, a Comissão de Educação da ABEn elaborou proposta para a revisão do currículo mínimo do Curso de Enfermagem e Obstetrícia, propondo a distribuição semestral das disciplinas, com dois semestres básicos e seis de formação profissional, incluindo a Enfermagem de Saúde Pública. No último ano, as alunas podiam optar entre Enfermagem Obstétrica, Enfermagem da Comunidade e Enfermagem Médico-Cirúrgica (CARVALHO, 1976).

Ainda naquele ano, no Seminário realizado na Escola de Enfermagem da Universidade de São Paulo (EEUSP), a discussão central abordou o currículo do curso de graduação em Enfermagem, tendo sempre presente a tentativa de manter os 4 anos de duração do curso. O currículo experimental apresentado pela EEUSP previa a inclusão da disciplina Enfermagem em Saúde Pública e apresentava a preocupação com o melhor aproveitamento do tempo de estudos e a possibilidade do estudante trabalhar (CARVALHO, 1976). Para tanto propunha a redução das férias e da carga horária prática de campo, à semelhança das atuais Diretrizes Curriculares para o Ensino de Graduação em Enfermagem. Em 1968, a justificativa principal era a redução da evasão e permitir que o aluno pudesse trabalhar, como faziam outros universitários, sem abandonar o curso. Hoje, a razão principal parece ser a diminuição dos custos dos cursos de graduação de enfermagem, com o oferecimento de maior número de disciplinas teóricas, que podem ser ministradas simultaneamente para um contingente bem maior de alunos. Vale dizer que a redução de custos favorece prioritariamente as escolas privadas, cujo número tem crescido significativamente, em especial no estado de São Paulo.

\subsection{0 curriculo minimo de 1972}

Em consonância com um capitalismo favorável ao consumo desmedido de medicamentos, bem como a indústria de equipamentos médicocirúrgicos, fundamentais às empresas de saúde, o Parecer CFE n.163/72 reformulou o currículo mínimo de enfermagem, criando as habilitações em Saúde Pública, Enfermagem Médico-cirúrgica e Obstetrícia, para serem cursadas de forma optativa. Para GERMANO (1985), o Parecer n.163/72 enfatizava a necessidade do enfermeiro dominar cada vez mais as técnicas avançadas em saúde, em razão da evolução científica, uma vez que a profissão médica passara a necessitar de uma enfermagem especializada para juntas atuarem na assistência curativa. Contudo, a especialização dava-se durante a graduação, prejudicando a formação mais geral. Entretanto, essa formação não era onerosa ao sistema de ensino, o que ocorreria se a especialização fosse em nível de pósgraduação (RIZZOTTO, 1999).

Desde a sua proposição, o currículo mínimo de 1972 foi questionado por um segmento de enfermeiras engajadas com as questões relacionadas ao ensino de enfermagem, em relação à fragmentação do eixo da formação, à ênfase dada ao modelo hospitalar, à especialização precoce decorrente das habilitações e à denominação composta para designar o curso (Enfermagem e Obstetrícia). Tais questões foram resgatadas nas discussões posteriores que subsidiaram a elaboração do currículo mínimo de 1994 (ABEn, 1991).

A atuação da ABEn na conformação dos currículos de enfermagem vigentes até então no país havia sido criticada por GERMANO (1985): "a $A B E n$ exerceu e continua exercendo decisiva influência na história do ensino da enfermagem no Brasil... [porém]... não é possivel, por outro lado, obscurecer, ao longo de sua existência, seu apoio no sentido de legitimar as políticas de educação e de saúde oriundas do Estado brasileiro, nem sempre condizentes com as necessidades básicas dos setores subalternos da população e a influência dessas políticas na formação e prática desses profissionais de enfermagem".

Entretanto, na década de 80, em consonância com os movimentos sociais que integravam o projeto mais geral de redemocratização da sociedade brasileira, também na Enfermagem evidenciou-se a necessidade de uma ampla reforma na prática profissional como resultado da construção coletiva de uma nova direção 
intelectual, moral e política para a enfermagem Mas é na formação do enfermeiro que a sua brasileira, a começar pela entidade representativa, o interferência será maior e as definições mais precisas. O que se materializou na chapa de oposição da ABEn. O papel assumido pela Comissão de Educação foi de Movimento Participação tinha como propósito aliar- facilitar as reflexões com vistas à transformação, se ao projeto da Reforma Sanitária, comprometido com buscando resgatar as experiências acumuladas pelas mudanças nas condições de vida das populações mais escolas de enfermagem. Para MOURA (1997), o salto necessitadas. A redefinição da política de formação e, na qualidade da ação da Comissão de Educação é que consequentemente, do trabalho da enfermagem, eram seus intelectuais possuiam clareza do horizonte a ser algumas de suas prioridades (MOURA, 1997).

A crise econômica e política que atingiu de forma expressiva a área da saúde fez parte dos debates para proposição do Sistema Único de Saúde (SUS), com a responsabilidade de planejar e a executar a politica nacional de saúde. A definição de novas diretrizes educacionais para a enfermagem demandava a incorporação de conteúdos que proporcionassem o do enfermeiro reiterou as críticas anteriormente feitas exercício de novas atribuições para atender as ao Currículo Mínimo de 1972 e necessidades sociais. Intensificaram-se as criticas ao currículo vigente, destacando-se a exclusão do ensino da saúde pública do tronco profissional comum.

\subsection{0 currículo minimo de 1994}

"Mais uma vez, é a Comissão de Educação da construção coletiva de novas diretrizes para o ensino $A B E n$ que vai plasmar e veicular a concepção de de enfermagem, em 1994, o CFE reformulou o educação a ser adotada. No entanto, diferentemente currículo mínimo, através do Parecer n.314/94. A carga do que ocorrera em momentos anteriores, a concepção horária minima passou a ser de 3.500 horas/aula, de educação veiculada pela comissão vai estar incluindo as 500 horas destinadas ao estágio comprometida com a construção da contra-hegemonia curricular, com duração não inferior a dois semestres na enfermagem" (MOURA, 1997).

Concomitantemente aos debates da criação do SUS, a ABEn, as Escolas de Enfermagem e a Comissão de Especialistas de Enfermagem da Secretaria de Educação Superior (SESu) do MEC buscaram reorientar a estrutura da formação do enfermeiro. Realizam-se seminários regionais, oficinas de trabalho e comitês específicos e finalmente o Seminário Nacional sobre Currículo Mínimo para a Formação do Enfermeiro, no Rio de Janeiro, em 1989.

Em 1991 foi encaminhada uma proposta de reformulação do currículo mínimo fundamentada em discussões sobre o perfil sanitário e epidemiológico da população, a organização dos serviços de saúde, o processo de trabalho em enfermagem e a articulação entre o ensino e os serviços (CHRISTÓFARO, 1991). letivos e desenvolvido sob supervisão docente. Buscava assegurar a participação do enfermeiro dos serviços de saúde no ensino através de propostas de integração docente-assistencial, proposição não teve diferentes interpretações. Permitiu inclusive o entendimento de que supervisão do estágio curricular poderia ser feita à distância, desde que ancorada em um projeto de integração docente-assistencial.

$\mathrm{O}$ artigo $3^{\circ}$ definiu que os currículos plenos dos cursos de graduação em enfermagem deveriam conter disciplinas relativas às Ciências Biológicas e Humanas e quatro áreas temáticas, tal como se segue: "Bases Biológicas e Sociais da Enfermagem, Fundamentos da Enfermagem, Assistência de Enfermagem $e$ Administração em Enfermagem" (BRASIL, 1994).

Os conteúdos relativos à Saúde Pública, As reformulações incluíam a extinção das habilitações, excluídos do currículo mínimo anterior, retornaram o aumento de carga horária, o redimensionamento dos sob a designação de Saúde Coletiva. Entretanto, conteúdos das ciências humanas e biológicas, a manteve-se a subdivisão em especialidades médicas valorização do compromisso com a sociedade e a na área temática Assistência de Enfermagem, reflexão sobre a prática profissional. Considerava perfil evidenciando a dificuldade de ruptura com a matriz sanitário e epidemiológico da população, a organização flexneriana que orientou o ensino de Enfermagem dos serviços de saúde, o processo de trabalho em desde seu início no Brasil.

enfermagem e a articulação entre o ensino e os serviços (CHRISTÓFARO, 1991).Essa proposta resultou no Parecer n.314/94, de 6 de abril de 1994.

Seus principais avanços dizem respeito ao movimento político gerado pela categoria para a sua definição e ao processo coletivo de sua construção. O

Merece destaque o fato de a Comissão de interesse em considerar "o perfil epidemiológico $e$ Educação da ABEn ter como proposta de trabalho quadro sanitário do País/Região/Estado" (BRASIL, atuar nos três niveis de formação ou seja, o nivel 1994) demonstra a preocupação com as distintas médio, a graduação e a pós-graduação em enfermagem. realidades do país e a divisão por áreas temáticas 
permite maior dinamicidade ao ensino. No entanto, a preservação da matriz flexneriana resulta em uma formação prioritariamente voltada à assistência curativa e individual.

\section{A LEI DE DIRETRIZES E BASES DO ENSINO E AS DIRETRIZES PARA O ENSINO DE ENFERMAGEM NA ATUALIDADE}

Em 23 de dezembro de 1996, foi publicada no Diário Oficial da União a nova Lei de Diretrizes e Bases da Educação (LDB), Lei n.9.394 de 20 de dezembro de 1996 que, repetindo o texto da Constituição Federal, reiterou a perspectiva vigente que atribui a responsabilidade da educação à família e ao Estado, já contida na LDB de 1961. Do ponto de vista da educação superior, reforçou a atual tendência profissionalizante, bastante questionada, na qual a formação global é escassamente considerada (BELLONI, 1997).

A LDB trouxe novas responsabilidades para as Instituições de Ensino Superior (IES), docentes, discentes e sociedade, pois permite a formação de diferentes perfis profissionais a partir da vocação de cada curso/escola, esperando melhor adaptação ao "mundo do trabalho", já que as instituições terão liberdade para definir parte considerável de seus currículos plenos.

Em 1997, o MEC, por intermédio da SESu, tornou público e convocou as Instituições de Ensino e as associações profissionais interessadas a participar e apresentar propostas para discussão das novas Diretrizes Curriculares para os cursos superiores. Tal convocação desencadeou a realização de Seminários Nacionais de Diretrizes para a Educação em Enfermagem no Brasil (SENADEn), promovidos pela ABEn, com o objetivo geral de discutir e estabelecer as diretrizes gerais para a educação em enfermagem, articulando os diversos níveis de formação.

No $2^{\circ}$ SENADEn, no conjunto das questões referentes ao ensino de graduação, destacava-se a existência de muitos cursos com ênfase no modelo biomédico, com dissociação entre a teoria e a prática. No $3^{\circ}$ SENADEn, delineou-se o perfil da enfermeira cujas características foram assim sintetizadas: "profissional generalista, crítico e reflexivo, com competência técnico-científica, ético-politico, social e educativa" (SENADEn, 1998). Quanto aos conteúdos essenciais, foram mantidos aqueles propostos pelo Parecer CFE n.314/94, com exceção das Ciências Humanas, em que foram acrescidos os conteúdos de Filosofia e Comunicação, e também da Psiquiatria, que passou a ser designada Psiquiatria/Saúde Mental.
As propostas de Diretrizes do Ensino Superior foram discutidas e sistematizadas pela Comissão de Especialistas em Enfermagem da SESu/MEC. Em dezembro de 1998, foram divulgados os primeiros documentos-sintese e solicitadas novas contribuições às IES para a elaboração da sua versão final.

Em julho de 1999, a proposta sobre as Diretrizes do Ensino de Enfermagem, pautada tanto nos documentos encaminhados pelas IES e pela ABEn, em conformidade com o "Modelo de Enquadramento das Propostas de Diretrizes Curriculares" formulado pelo Departamento de Politicas de Ensino Superior - SESu/ MEC , postulou:

"a constituição da estrutura do curso deverá garantir os princípios de autonomia institucional, de flexibilidade (incluindo as disciplinas obrigatórias e optativas) e pluralidade no currículo assim como a possibilidade de opção do corpo discente. Deve haver no currículo a possibilidade de opção por conteúdos que gerem competências especificas(habilitações) nas seguintes grandes áreas de formação: bacharel, formação aplicada profissional, formação de docentes e formação de pesquisadores perfazendo um minimo de 500 horas por habilitação ".

As IES deveriam compor um curso respeitando o minimo de 4.000 horas-aula e oito semestres letivos. O estágio curricular deveria ser no minimo de 500 horas, sob coordenação docente e contando com a participação de enfermeiros dos serviços de saúde. O estágio curricular não deveria substituir o ensino clínico ${ }^{2}$, previsto como atividade complementar. A proposta privilegiava a formação do enfermeiro "crítico e reflexivo com competência técnico-científico-éticopolitico-social-educativa" (BRASIL, 1999):

A flexibilidade contida na nova LDB dá as IES a liberdade de determinar o perfil de aluno que deseja formar, o que representa um avanço, porém o ensino tem sido determinado pelos interesses dominantes, voltados para um mercado de trabalho que atende as necessidades de uma minoria. Profissionais e educadores devem estar atentos e compromissados com um ensino que proporcione mudanças capazes de atender a sociedade e suas necessidades de saúde.

Ainda em 1999, no Fórum Nacional de Cursos, Escolas e Faculdades de Enfermagem realizado em Florianópolis, durante o $51^{\circ}$ Congresso Brasileiro de Enfermagem e $10^{\circ}$ Congreso Panamericano de Enfermería, discutiu-se amplamente a Proposta de Enquadramento das Diretrizes Curriculares. Considerou-se que a mesma "põe em risco os eixos norteadores da proposta politico-pedagógica construida coletivamente durante as décadas de 80 e 90", estabelece uma concepção fragmentada do processo ensino-aprendizagem, impossibilita às IES a implantação de seu próprio projeto pedagógico, não propicia a formação integral do profissional, 
principalmente ao introduzir a especialização precoce, e permite a inserção da modalidade do curso seqüencial (ABEn, 1999).

O documento sintese que resultou das discussões plenárias indicou que a flexibilização curricular deve compreender uma estrutura dinâmica passivel de adaptações e de atualizações que garantam o redimensionamento dos perfis de formação, que a formação do bacharel em enfermagem deve ser garantida e obrigatória, que a duração mínima do curso deve ser de 3.500 hora/aula e oito semestres letivos, incluindo o estágio supervisionado e a realização de monografia para sua conclusão (ABEn, 1999).

Em abril de 2000, em continuidade às discussões, realizou-se em Fortaleza o $4^{\circ}$ SENADEn, com o tema central "Enfermagem: tendências e perspectivas político-pedagógicas", cujas recomendações finais podem ser assim sintetizadas: as competências e habilidades do bacharel em Enfermagem devem assegurar a articulação entre o ensino, a pesquisa e a extensão, sem a retomada das habilitações; não devem ser oferecidos cursos seqüenciais de formação específica e/ou complementação; o estágio curricular supervisionado deve corresponder a atividades que dão terminalidade ao curso de graduação e deve efetivar a articulação ensino-serviço e a avaliação institucional deve ser balizada pelo projeto politico-pedagógico dos cursos e norteada por critérios construídos coletivamente (SENADEn, 2000).

\section{CONSIDERAÇÕES FINAIS}

A incapacidade dos serviços de saúde de atender de forma equânime toda a população colocou à prova o modelo que enfatiza o paradigma flexneriano, modelo este que permeou o ensino de enfermagem por quase sessenta anos. A conceituação de Atenção Primária de Saúde trouxe um discurso contra-hegemônico e gerou idéias que se incorporam em modelos como o da Vigilância à Saúde e, conseqüentemente, demandaram novas práticas e novas políticas caracterizando a Reforma Sanitária. Apesar de todo este movimento, as transformações na formação dos profissionais de saúde ainda tem pouca ou quase nenhuma relação com a Reforma Sanitária (KISIL, 1998).

A Enfermagem tem procurado construir um corpo específico de conhecimentos em busca de autonomia e especificidade. As teorias de Enfermagem representam uma tentativa nessa direção, porém enfocam predominantemente a prática hospitalar, o combate às doenças e a recuperação da saúde. A dimensão coletiva da promoção da saúde e da prevenção do adoecimento dentro da perspectiva do ensino tem sido praticamente desvinculada das teorias da Enfermagem. (MEYER,1998), exceção feita à teorização proposta por EGRY (1996) na Teoria de Intervenção Práxica da Enfermagem em Saúde Coletiva (TIPESC).

A construção coletiva de diretrizes para o ensino da Enfermagem, nas duas últimas décadas, representa um avanço. No entanto, apesar de todas as mudanças ocorridas nos programas e currículos de enfermagem, o modelo flexneriano ainda se mantém hegemônico na formação da enfermeira. A enfermagem tem reproduzido o ensino médico, inclusive quanto à grade curricular, procurando desenvolver-se para acompanhar a tecnologia existente e organizando-se de maneira a propiciar condições de funcionamento das instituições hospitalares nas diversas especializações. As questões de saúde pública nunca foram priorizadas, temos formado enfermeiros que atendam às necessidades do mercado de trabalho e dos grupos dominantes.

Na esteira do Currículo Mínimo de 1994, alguns Cursos de Enfermagem realizaram mudanças curriculares inovadoras, ainda que lentas. Frente às Diretrizes Curriculares é necessário analisar a proposta atual, redimensioná-la, garantir a flexibilidade, sem desviar dos eixos norteadores contidos na Carta de Florianópolis (ABEn, 1999).

A compreensão mais crítica da articulação entre educação e saúde é enfatizada predominantemente no âmbito da Saúde Coletiva que, dentro das suas perspectivas, procura situar o indivíduo em um contexto sócio-cultural específico, bem como compreender a determinação social do processo saúdedoença (MEYER, 1998).

A produção dos serviços de saúde é também determinada pela formação em saúde, o objeto da saúde coletiva necessita de um olhar interdisciplinar, da articulação disciplinar para uma efetiva integração dos diferentes campos de saber, que se complementam pelas diferentes formas de recortar o objeto. A formação dentro desse novo paradigma de saúde e educação poderá gerar condições capazes de transformar a realidade, visando atender às necessidades da população, dentro das proposições do Sistema Único de Saúde. 


\section{REFERÊNCIAS BIBLIOGRÁFICAS}

ALCÂNTARA, G. A enfermagem moderna como categoria profissional: obstáculos à sua expansão na sociedade brasileira. Ribeirão Preto, 1963. Tese (Provimento de Cátedra) - Escola de Enfermagem de Ríbeirão Preto, Universidade de São Paulo.

ALMEIDA, MCP.; ROCHA, JSY. O saber de enfermagem sua dimensão prática. São Paulo, Cortez, 1989.

GARCIA, T.R; CHIANCA,T, C.M.; MOREIRA, A.S.P. Retrospectiva histórica do ensino de enfermagem no Brasil e tendências atuais. Rev Gaúcha Enf, v.16, n.1/2, p.'74-81, 1995.

e GERMANO, R.M. Educação e ideologia da enfermagem no Brasil. São Paulo, Cortez, 1985.

ASSOCIAÇÃO BRASILEIRA DE ENFERMAGEM. Proposta de novo curriculo minimo para o curso superior de enfermagem: a formação do enfermeíro. Brasília, 1991.

ASSOCIAÇÃO BRASILEIRA DE ENFERMAGEM. Documento final da Reunião Nacional de Cursos e Escolas de Graduação em Enfermagem. Carta de Florianópolis. Florianópolis, 1999.

BARREIRA, IA. Transformações da prática da enfermagem nos anos 30. Rev Bras Enf, v.52, n.1, p.129-43, 1999.

BELLONI, I. A educação superior na nova LDB. In: BRZEZINSKI, I (org.) LDB Interpretada: diversos olhares se intercruzam. São Paulo, Cortez, 1997. p.123-40.

BRASIL. Portaria n.1721, de 15 de dezembro de 1994. Fixa os mínimos de conteúdos e duração do curso de enfermagem. Diário Oficial da União, Brasília, 16 de dez. 1994. Seção 1, p. 19801-2.

BRASIL. Lei n.9.394, de 20 de dezembro de 1996. Estabelece as diretrizes e bases da educação nacional. Diário Oficial da União. Brasília, 23 de dez. 1996. Seção 1, p.27.833-41.

BRASIL. Ministério da Educação e do Desporto. Secretaria de Educação Superior-SESu. Chamada de propostas. Brasília, 1997.

BRASIL. Ministério da Educação. Secretaria de Educação Superior. Departamento de Politica de Ensino Superior. Coordenação das Comissões de Especialistas de Ensino. Comissão de Especialistas de Enfermagem. Diretrizes Curriculares para os Cursos de Graduaçãode Enfermagem . Brasília, 1999.

CARVALHO, A.C. Orientação e ensino de estudantes de enfermagem no campo clínico. São Paulo, 1972. 126p. Tese (Doutorado) - Escola de Enfermagem, Universidade de São Paulo.

CARVALHO, AC. Associação Brasileira de Enfermagem 1926-1976: Documentário. Brasília, Folha Carioca, 1976.

CHRISTÓFARO, MAC. Currículo Mínimo para Formação do Enfermeiro: na ordem do dia. Rev Bras Enf, v.44, n.213, p.'7-9, 1991.

DUCHIADE, MP. População brasileira: um relato em movimento. In: MINAYO, M.C.S. (org.) Os muitos brasis: saúde e população na década de 80. São Paulo, Hucitec, 1995. p. 14-56.
EGRY, EY. Saúde coletiva: construindo um novo método em enfermagem. São Paulo, ícone, 1996.

FRAENKEL, E. Histórico do serviço de enfermeiras do Departamento Nacional de Saúde Pública. Rev EE Anna Nery, v.1, n.1, p.9-12, 1997. (Texto, fac-simile)

\section{GERMANO, JW. Estado Militar e educação no Brasil}

(1964.1985). São Paulo, Cortez, 1993.

KISIL, M. Prefácio. In: CHOMPRÉ, RRS.; EGRY, EY. A enfermagem nos projetos Uni: contribuição para um novo projeto político para a enfermagem brasileira. São Paulo, Hucitec, 1998, p.7-13.

MEYER, DE. Espaços e sombra de luz: reflexões em torno da dimensão educativa da enfermagem. In: MEYER, DE.; WALDOW, V.; LOPES, MJM. (org.) Marcas da diversidade: saberes e fazeres da enfermagem contemporânea. Porto Alegre, Artes Médicas, 1998. Cap.2, p.27-42.

MOURA, A. A produção da força de trabalho da enfermagem no nivel de terceiro grau. São Paulo, 1997. 197p. Tese (Doutorado) - Escola de enfermagem, Universidade de São Paulo.

OLIVEIRA, FVS. Associação Brasileira de Enfermagem: mudanças e continuidades - A propósito do movimento participação (1979-1989). Natal, 1990. 203p. Dissertação (Mestrado) - Departamento de Enfermagem, Universidade Federal do Rio Grande do Norte.

PAIVA, MS et ai. Enfermagem brasileira: contribuição da ABEn. Brasília, ABEn Nacional, 1999.

PAIXÃO, V. Páginas de história da enfermagem. Rio de Janeiro, Universidade do Brasil, 1951.

RIZZOTTO, MLF. História da enfermagem e sua relação com a saúde pública. Goiânia, AB, 1999.

SALUM, MJL.; BERTOLOZZI, MR.; OLIVEIRA, MAC. O coletivo como objeto da Enfermagem: continuidades e descontinuidades da história. In: ORGANIZACIÓN PANAMERICANA DE LA SALUD. La enfermeria en las américas. Washington, DC.,1999. p.101-18. (publicação científica 571)

S E M I N ÁRIO N A C I O N A L D E E D U C A ÇÃ O E M ENFERMAGEM NO BRASIL, SENADEn.2. Florianópolis, 1997. Relatório. Florianópolís, ABEn/UESC, 1997.

SEM I N ÁRIO N A C I O N A L D E D U C A ÇÃ O E M ENFERMAGEM NO BRASIL, SENADEn. 3. Rio de Janeiro, 1998. Relatório. Rio de Janeíro, ABEn/UERJ, 1998.

S E M I N ÁRIO N A C I O N A L D E E D U C A Ç Ã O E M ENFERMAGEM NO BRASIL, SENADEn. 4. Fortaleza, 2000. Relatório preliminar. Fortaleza, ABEn-seção Ceará, 2000.

\section{Artigo recebido em 01103100}

Artigo aprovado em 01106101 